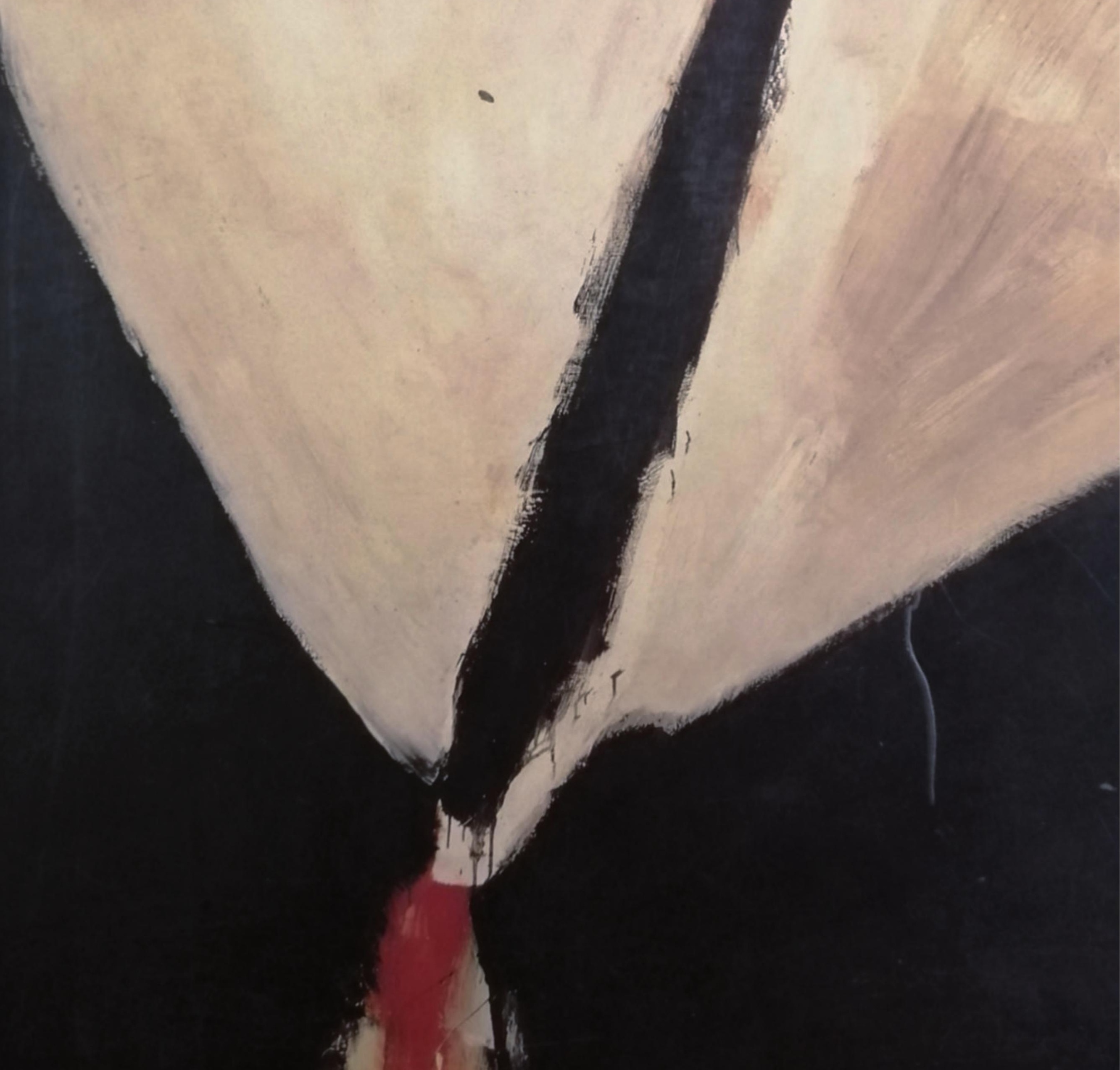




\title{
Andalucía en la contemporaneidad: 1978-2008. Aproximación a las construcciones de unas identidades plásticas a través del catálogo artístico
}

\author{
Andalusia in the Contemporary Era: 1978-2008. An Approach to the Construction \\ of Visual Identities through Art Catalogs
}

\author{
Iván de la Torre Amerighi \\ Universidad de Málaga, España \\ ita@uma.es
}

https://orcid.org/0000-0002-2550-7938

Recepción: 26/01/2020 | Aceptación: 19/03/2020

\begin{abstract}
Resumen
El catálogo de arte, el catálogo expositivo, supone una de las principales herramientas que posibilitan la comprensión de una determinada época de modo multidimensional. Las posibilidades de recrear una historia del arte producido en Andalucía a través de los catálogos expositivos durante un periodo delimitado de su historia reciente resulta empresa factible, del mismo modo que constatar en ellos las sinergias, intereses y objetivos que animaron la voluntad por difundir y defender determinados rasgos -y no otros- como constitutivos de la idiosincrasia del arte andaluz contemporáneo durante el último cuarto del siglo XX y la primera década deI XXI. A través del estudio de un número limitado de casos es posible analizar la posibilidad o imposibilidad de establecer los rasgos configurativos de un arte contemporáneo andaluz desde un punto de vista sentimental y estético.
\end{abstract}

Palabras clave

Arte contemporáneo
Andalucía
Política cultural
Libro de arte
Catálogos
Exposición de arte

Keywords

Contemporary Art
Andalusia
Cultural Policy
Art Books
Catalogs
Art Exhibitions

\begin{abstract}
The art catalog or the exhibition catalog, is one of the main tools that enable us to understand a particular era in a multidimensional way. It is feasible to recreate a history of art produced in Andalusia during a specific period in its recent history through its exhibition catalogs. In them, we note synergies, interests, and objetives that encouraged the will to spread and defend certain features -and not others- as constitutive of the idiosyncrasies of contemporary Andalusian art during the last quarter of the twentieth century and the first decade of the twenty-first. Through the study of a limited number of cases, it is possible to analyze the possibility or impossibility of establishing the defining characteristics of Andalusian contemporary art from a sentimental and aesthetic perspective.

Abstract
\end{abstract}

Cómo citar este trabajo / How to cite this paper:

De la Torre Amerighi, Iván. "Andalucía en la contemporaneidad: 1978-2008. Aproximación a las construcciones de unas identidades plásticas a través del catálogo artístico." Atrio. Revista de Historia del Arte, no. 26(2020): 266 - 290. https://doi.org/10.46661/atrio.4568

(C) 2020 Iván de la Torre Amerighi. Este es un artículo de acceso abierto distribuido bajo los términos de la licencia Creative Commons Attribution-NonCommercial-ShareAlike 4.0. International License (CC BY-NC-SA 4.0). 


\section{Introducción}

A partir de 1975 y con el desarrollo de la transición española, que desembocaría en la instauración de un sistema democrático y en el Estado de las autonomías, algunas regiones españolas comenzaron a implementar dispositivos de justificación y desarrollo de la idea de un capital creativo propio y singular. Si bien no se trató de una estrategia de resurrección de los regionalismos artísticos, aunque algunas actuaciones apuntaran hacia un ámbito demasiado afín, los gobiernos autonómicos y las instituciones públicas locales y provinciales en general, y algunas iniciativas privadas en particular, se afanaron en la defensa de las singularidades y particularidades de un arte propio frente al de otros territorios nacionales.

Este impulso se canalizó a través de la promoción y el patrocinio de una herramienta, la exposición, y de su extensión inseparable, el catálogo, para defender los rasgos diferenciales de un espacio artístico concreto, un ámbito que discurría en paralelo a la evolución de los formatos -expositivos, catalogares...- desplegados para difundirlo y otorgarle carta de identidad.

\section{La identidad antes de la identidad}

Pintores andaluces desde 1900’ fue una exposición patrocinada por el Banco de Granada que, además de ser exhibida en las salas de la institución entre febrero y marzo de 1978, había recalado con anterioridad en Valencia(diciembre de 1977), Málaga -se expuso en el Museo Provincial de Bellas Artes en enero de 1978- y Sevilla -enero-febrero de 1978 en el Museo de Arte Contemporáneo-. La propuesta unía tres generaciones de heterogéneos artistas andaluces ${ }^{2}$. Los textos que acompañan al catálogo de obras presentes en la muestra manifestaban de modo elocuente las procelosas aguas en las que se movieron, durante la etapa de la Transición y el periodo inmediatamente posterior, el arranque y desarrollo del Estado de la autonomías, historiadores y críticos de arte. La problemática

* Este trabajo forma parte de los resultados de investigación del proyecto de I+D "Catálogos artísticos: gnoseología, epistemologías y redes de conocimiento. Análisis crítico y computacional" (HAR2014-51915-P).

1. Pintores andaluces desde 1900 (Granada: Banco de Granada, 1977).

2. La exposición contó con obras de Gustavo Bacarisas, Manuel Barbadillo, Gonzalo Bilbao, Enrique Brinkmann, Pedro Bueno, José Caballero, Francisco Cortijo, Alfonso Fraile, Eugenio Gómez-Mir, Luis Gordillo, José Guerrero, Carmen Laffón, J. M. López Mezquita, Francisco Mateos, Gabriel Morcillo, Manuel Ángeles Ortiz, Ginés Parra, Francisco Peinado, Joaquín Peinado, Jesús de Perceval, Pablo Picasso, Manuel Rivera, J. M. Rodríguez-Acosta, Julio Romero de Torres, Juan Romero, Ismael de la Serna, Cristóbal Toral, Antonio Valdivieso, Joaquín Valverde, Daniel Vázquez Díaz y Rafael Zabaleta. 
se planteaba ante la pertinencia o no, ante la posibilidad o imposibilidad, de recuperar y ofrecer visibilidad a una realidad, la del arte contemporáneo de la periferia, a partir de la tentación del restablecimiento de la noción de escuelas regionales.

En la interesante introducción sobre las motivaciones para patrocinar el proyecto, Miguel-Ángel Revilla Uceda, director de la galería de exposiciones del Banco de Granada y autor de una imprescindible monografía sobre el pintor José María Rodríguez-Acosta ${ }^{3}$, negaba con rotundidad que dicha muestra antológica fuera un intento de proposición o reconocimiento de una suerte de escuela andaluza de pintura contemporánea. Renunciaba, incluso, a que el proyecto fuera interpretado como la reunión de "una serie de realizaciones en donde palpitaría un mismo espíritu y contenido cultural"4. Pocas líneas más abajo, sin embargo, defendía la propuesta como "una manera de contribuir a la búsqueda de aportaciones plásticas periféricas, a veces marginadas, y reconocer la legítima exigencia de dar cauce a los valores culturales asfixiados por una concepción rígidamente centralista de nuestra cultura nacional"5.

En el otro texto catalogar, obra del profesor Julián Gállego, que comenzaba preguntándose qué era la pintura andaluza y qué era lo andaluz, se deslizaban un tono, una intención y unas proposiciones muy diferentes. Apoyándose en algunas definiciones desplegadas en Teoría de Andalucía por Ortega y Gasset, especialmente aquella que dictaba que sin haber desarrollado nunca una voluntad de diferenciación o emancipación, Andalucía entre las regiones españolas, era la que poseía una cultura más radicalmente suya, entendiendo cultura como sistema de actitudes ante la vida con ordenado sentido, coherencia y eficacia, el historiador del arte se atrevía a advertir que "si algo diferencia Andalucía de las demás regiones españolas, acaso sea la abundancia de artistas que engendra, en la poesía, en la música, en la danza, en las artes plásticas. Contadas serían las regiones españolas que pudieran exponer un nutrido conjunto de pintores, de tan satisfactorio nivel" ${ }^{\prime \prime}$.

Es posible vislumbrar ya otros de los conceptos que, unidos, tal y como como veremos, van a perpetuarse a lo largo de décadas como hechos diferenciales en el tiempo: la abundancia, diversidad y calidad del arte andaluz en general y una identidad híbrida, universal y local, que identificaría al artista andaluz, en particular. Un creador que, aun

\footnotetext{
3. Miguel-Ángel Revilla Uceda, José María Rodríguez Acosta, 1878-1947(Madrid: Turner, 1992).

4. Miguel-Ángel Revilla Uceda, "Prólogo," en Pintores andaluces desde 1900, s. p.

5. Revilla Uceda, s. p.

6. Julián Gállego, "Pintores andaluces desde 1900," en Pintores andaluces desde 1900, s. p.
} 


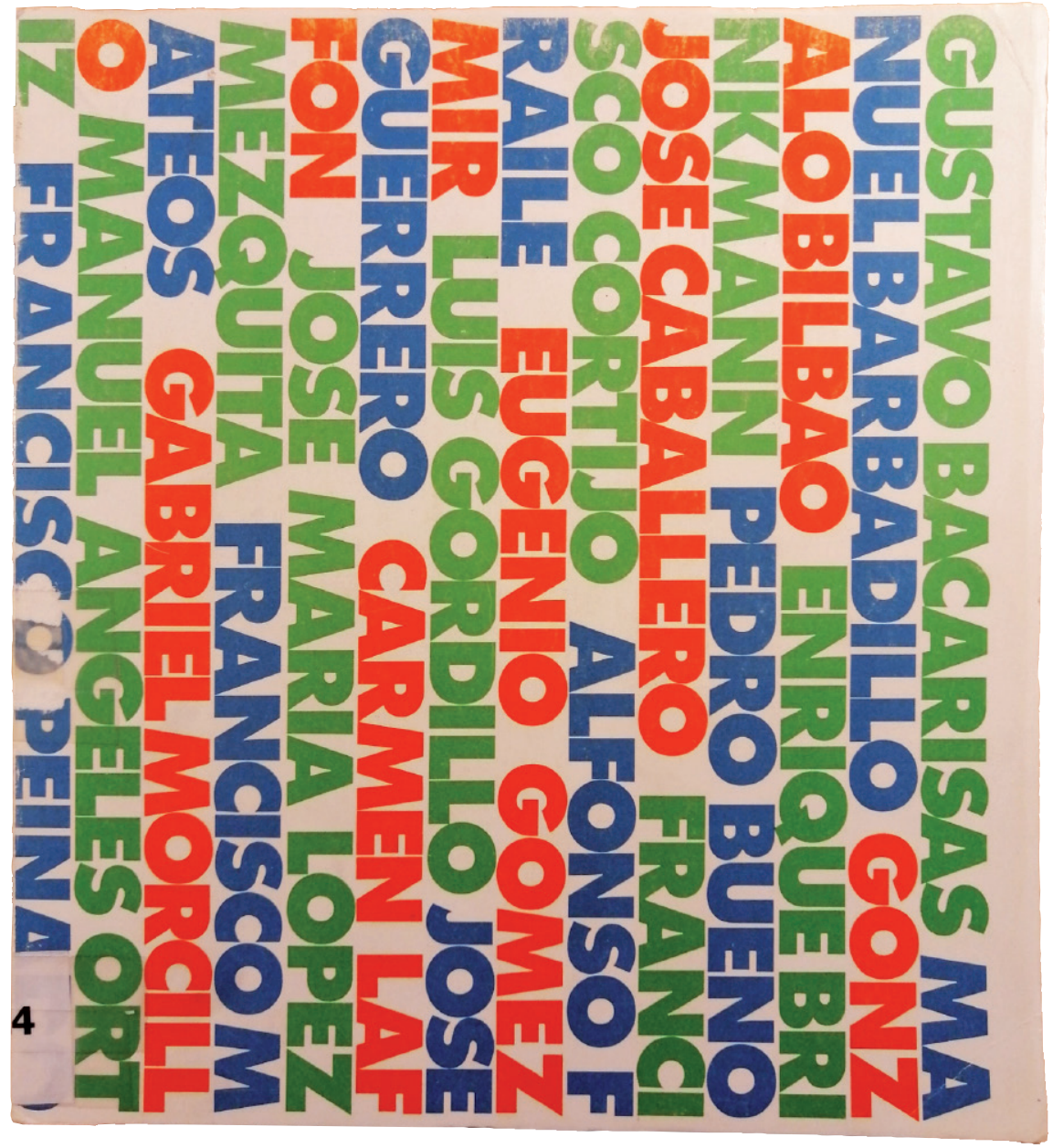

Fig. 1. Pintores andaluces desde 1900. 1977. Catálogo. Banco de Granada. habiendo abandonado su tierra para fraguarse un futuro y un nombre, nunca deja de sentirse andaluz.

Casi contemporáneamente, entre febrero y marzo de 1978, la Universidad de Sevilla impulsó la I Exposición de Pintores Andaluces Contemporáneos ${ }^{7}$, con obras de Barbadillo, Brinkmann, Caballero, Gordillo, Guerrero, José Hernández, Perceval, Povedano, Juan Romero y Antonio Valdivieso. El catálogo contó con un breve texto introductorio de José María Moreno Galván, en el cual el crítico de arte deslizaba algunas preclaras intuiciones.

Vislumbraba Galván que en el mundo del arte y de la pintura en particular se estaba operando un cambio sus-

tancial. Esta transformación atendía al progresivo relegamiento de los grandes nombres imprescindibles que dotaban de carácter a una determinada esfera creativa en favor de una identificación vinculada a lo territorial. Intuía también el final de los academicismos, arrinconados por unas búsquedas individuales de los artistas que coincidían cada vez más con el camino universal del arte. Finalmente, alabada la propuesta universitaria más por las problemáticas que, desde su mismo título e intención, planteaba que por las soluciones que ofrecía: "lo más positivo que nos trae el hecho de la exposición de pintores andaluces, a mi ver, es que nos trae el problema que esa exposición nos plantea en sí mismo"8. Según el crítico andaluz, la existencia misma de una exhibición como aquella, proponía la posibilidad de considerar la existencia o no de una escuela pictórica andaluza, no únicamente a nivel de agrupamiento administrativo, sino como conciencia grupal.

7. IExposición de pintores andaluces contemporáneos (Sevilla: Universidad de Sevilla, 1978).

8. José María Moreno Galván, "Prólogo," en I Exposición de pintores andaluces contemporáneos, s. p. 


\section{La década de los 80: inicios de la autonomía. Presencia y diáspora}

En 1982 se desarrolló en el Museo de Bellas Artes de Bilbao la colectiva Pintores de Andalucía $^{9}$. El texto de Quico Rivas se tituló significativamente Rompecabezas andaluz. Notas sobre la historia del Arte Moderno en Andalucía. Extensísimo e interesante, mostraba nuevos modelos de elaboración de una narración plausible de la historia del arte andaluz contemporáneo, planteada como la desnuda arquitectura de una exposición sobre la pintura andaluza del siglo XX. Una muestra de artistas andaluces vivos, desde Manuel Ángeles Ortiz (1895) hasta Curro González (1960). Él mismo exponía la cuestión a dilucidar, que sería si el ser andaluz podía devenir "hoy en algo más que en unas cuantas 'notas fisiológicas', trasciende la forma de ser configurando una cultura con personalidad propia, más allá del folclore y las tradiciones populares. Y, más, en concreto, si esta cultura significa algo diferencial dentro de la pintura moderna"10.

También se cuestionaba sobre la necesidad y pertinencia de un análisis de tal cariz en el convencimiento de su imposible resolución. Aquella década -hoy mitificada- señaló el inicio de una eclosión generacional en las artes andaluzas, que obtuvieron masiva presencia en las exposiciones fundacionales de un nuevo tiempo artístico: 1980, en Juana Mordó; Madrid DF, en el Centro Municipal de la Villa, Madrid; y Panorama de la joven pintura española, en La Caixa, Barcelona. Esa emergencia fue también anunciada prematuramente por Rivas: "hasta el momento actual la aportación andaluza a la pintura moderna en España siempre había sido puntual, al contrario, por ejemplo, que en poesía. Por primera vez en el siglo XX resulta decisiva. A los numerosos y tristes records que detentamos (...) viene a añadirse otro, de carácter tan distinto que, confío, será otra de las realidades a tener en cuenta por el Gobierno Autónomo -primero en la historia de Andalucía- que en el momento de redactar estas líneas se dispone a prestar juramento"11.

Los inicios de la década de los '80 supusieron en España un momento trascendente de lo que desde nuestra actual atalaya puede ser visto como un movimiento cíclico en la historia de las artes: la eterna lucha entre lo universal y lo local. Rivas detectó una nueva "regionalización del arte" mientras se preguntaba por la pertinencia de establecer una escuela andaluza, con la dificultad añadida que entrañaba la artificial construcción de constantes estilísticas o formales. Toda esa diatriba quedó enmarcada por una

\footnotetext{
9. Pintores de Andalucía (Bilbao: Museo de Bellas Artes de Bilbao, 1982).

10. Francisco Rivas, "Rompecabezas andaluz. Notas sobre la historia del Arte Moderno en Andalucía," en Pintores de Andalucía, s. p.

11. Rivas, s. p.
} 
serie de acontecimientos inmediatos y coyunturales. En la primera edición de la Feria Internacional de Arte Contemporáneo, ARCO, en 1982, el crítico Laszlo Glover defendió en una conferencia la emergencia de los "nuevos regionalismos", Achille Bonito Oliva -padre de la "Transvanguardia"- disertó en un simposio sobre el difícil equilibrio entre el lenguaje del internacionalismo, los dialectos locales y el genius loci, mientras el entonces omnímodo galerista Lucio Amelio acuñaba el término "Nuevo arte meridional" para etiquetar a un grupo de artistas por él representados, frente a la fría "producción nórdica"12.

Uno de los empeños más importantes de Rivas como investigador de la realidad artística andaluza fue el de tratar de ofrecer visibilidad a la diáspora creativa andaluza. Esos planteamientos, con el paso de los años, no serían bien acogidos por las instituciones públicas pues de algún modo demostraban el fracaso de la política cultural autonómica, impotente a pesar de la inversión para crear un tejido artístico -en los ámbitos galerístico, coleccionista o económico-racional y autosuficiente.

Uno de los grandes proyectos que pretendían ofrecer visibilidad a esa diáspora tomó forma en la convocatoria de 1982 de Andana $1^{13}$ y se denominó Pintores andaluces que viven fuera de Andalucía. Desplegada en primera instancia en el Museo del Flamenco de Jerez de la Frontera en diciembre de 1981, a principios del año siguiente se desarrolló en Cádiz, en el Palacio de la Diputación. Como justificación, en el texto de Rivas titulado Elogio de los que se fueron, se afirmaba que "los grandes pintores andaluces (...) de una manera intermitente o definitiva, han emigrado a lo largo del siglo para ensanchar el asfixiante horizonte académico que les rodeaba, para incorporarse al complejo devenir del arte moderno"14.

Al tiempo que señalaba los motivos seculares que habían impulsado la emigración cultural andaluza fuera del territorio, se reafirmaba en la inexistencia de una "pintura andaluza", aunque sí admitía la posibilidad de poder delimitar escuelas o grupos regionales o locales, del mismo modo que solo era posible reivindicar y desarrollar una cultura andaluza "si al referirnos a ella la entendemos o sobreentendemos como precipitado de muchas culturas distintas, sedimentada a lo largo de los siglos, enriquecida gracias a la

\footnotetext{
12. Jorge Luis Marzo, "Lo moderno como antimoderno. Apuntes sobre el arte oficialista español en la época de la Transición," en El poder de la imagen. La imagen del poder, eds. Margarita Ruiz Maldonado, Antonio Casaseca, y Francisco Javier Panera Cuevas (Salamanca: Ediciones Universidad de Salamanca, 2013), 206.

13. Andana 1. Pintores andaluces que viven fuera de Andalucía (Cádiz: Diputación Provincial de Cádiz, 1982).

14. Francisco Rivas, "Elogio de los que se fueron," en Andana 1. Pintores andaluces que viven fuera de Andalucía, s. p.
} 
libre circulación de pueblos y gentes, a sus diálogos y comercios, intercambios y roces que no cesan"15. Si algo podemos entender como componente adhesivo que unificaría el ser andaluz, este sería el recuerdo de unas vivencias y unos acentos que son vividos como nostalgia (nostaljia juanramoniana) avivada en el olvido.

El catálogo contaba, además, con un preámbulo de Antonio Gala, en el que se definía de nuevo lo andaluz como un modelo vital: "Andalucía es, sobre todo, una forma de estar ante la vida, de ser la vida, de verla transcurrir. Y eso tendrán en común, estén en donde quieran, sus pintores: el don junto al desdén"16. Finalizaba el es-

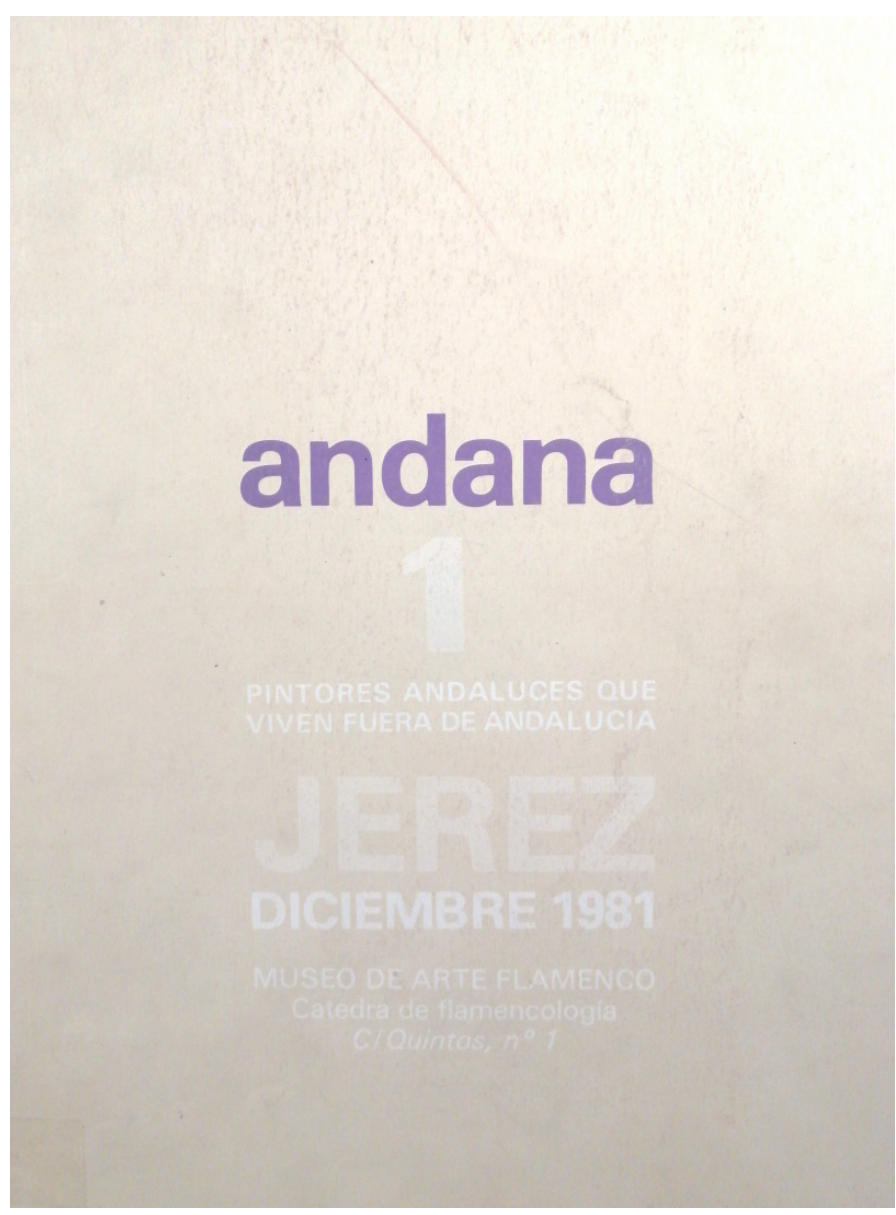

Fig. 2. Andana 1. Pintores andaluces que viven fuera de Andalucía. 1981. Catálogo. Ayuntamiento de Jerez de la Frontera. critor cordobés con un anhelo que, con el paso de los años, no se ha visto cumplido: "Hoy Andalucía, pródiga de hijos pródigos, favorece la vuelta alborozada. Hoy restaña parte de sus desangramientos. Hoy, sonriente y dispuestos los brazos, sale a la búsqueda de los buscadores..."17.

Ese proyecto tuvo su debido eco más allá de las fronteras de Cádiz e incluso de las andaluzas, pues ya nominado simplemente como Pintores andaluces que viven fuera de Andalucía fue exhibido ese mismo año de 1982 en Sevilla, en el Museo de Arte Contemporáneo, y en Madrid, en el Centro Cultural de la Villa.

Más de un lustro después, en 1988, la Caja General de Ahorros y Monte de Piedad de Granada, organizó Pintores andaluces en Madrid ${ }^{18}$. La muestra se pudo ver en las salas que la institución tenía en Granada (jardines del Triunfo) y Madrid (Fernando el Santo, 26). En

\footnotetext{
15. Rivas, s. p.

16. Antonio Gala, "Palabras ante una exposición," en Andana 1. Pintores andaluces que viven fuera de Andalucía, s. p.

17. Gala, s. p.

18. Pintores andaluces en Madrid (Granada: Caja General de Ahorros y Monte de Piedad de Granada, 1988).
} 
el texto, firmado por el crítico almeriense afincado en Madrid Antonio Manuel Campoy, una vez se había desgranado el elenco de artistas andaluces que fijaron a lo largo de la historia su residencia en Madrid, venía a preguntarse cuál era el aporte distintivo de estos, toda vez que en la muestra no había distinciones por agrupamiento ni por temáticas o tendencias, toda vez que el arte era cada vez menos nacional y más multinacional. Ese aporte distintivo, finalmente, pudiera ser "un ethos andaluz latiendo bajo la piel (...) y puede que también un pathos, pues lo andaluz funde y confunde lo bello con el dolor de sentirlo, la gracia y el Ilanto"19. Y es capaz de vislumbrarlo en obras tan dispares como las de José Guerrero, Manuel Rivera, Luis Gordillo, Ginés Liébana, Pepi Sánchez o Evaristo Guerra... Bien pudiera ser que todo ese ethos y ese pathos, como terminaba por reconocer Campoy, no fuera más que la manifestación de "una armonía de nostalgias de su origen. Como si viviera desterrada. Como si su alejamiento fuera transitorio. Un esperar la hora sagrada del regreso"20. Aún la nostalgia, nostalgia de una idea más que de un territorio, como fuente del carácter distintivo de cierto arte andaluz.

De nuevo, entre los componentes que identificarían el arte y a los artistas andaluces, además de la abundancia, calidad y diversidad, y de una identidad híbrida entre lo universal y lo local, emergería una suerte de ética que hace del júbilo un sentimiento de dimensión dramática -o viceversa-, y un sentimiento de nostalgia imperecedero, no tanto por "no estar", sino más bien por "no ser" ni tener expectativas de serlo.

\section{La exposición como herramienta de difusión institucional de una idea}

A mediados de la década de los '80 del siglo pasado, el arte andaluz tomó impulso a través de las exhibiciones institucionales. En esta tesitura de acontecimientos, anhelos y disposiciones, la administración pública vio en la exposición una herramienta propicia para cumplimentar intereses transversales y difundir una nueva imagen de Andalucía allende sus fronteras.

En 1985 la Junta de Andalucía patrocinó y organizó en el Palacio de Exposiciones IFEMA de Madrid, entre el 7 y el 17 de noviembre, una muestra -que a su vez acogía un conjunto de exposiciones, exhibiciones y actos de diversa índole- que ocupó una superficie de cinco mil metros cuadrados distribuidos en tres plantas cuya intención era recoger

19. Antonio Manuel Campoy, "Pintores andaluces en Madrid," en Pintores andaluces en Madrid, s. p. 20. Campoy, s. p. 
"una síntesis de la historia y la cultura andaluza, por un lado; las perspectivas económicas y principales empresas de la Comunidad Autónoma, por otro, así como el sector público andaluz..." ${ }^{21}$ y cuyos objetivos eran los de "ofrecer de cara a la integración en la CEE, en el umbral del siglo XXI, una síntesis del rico pasado andaluz y su potencial de futuro"22.

Arte y cultura, ante la perspectiva de la entrada en la Comunidad Económica Europea, y la necesidad de las autonomías de tomar posición,

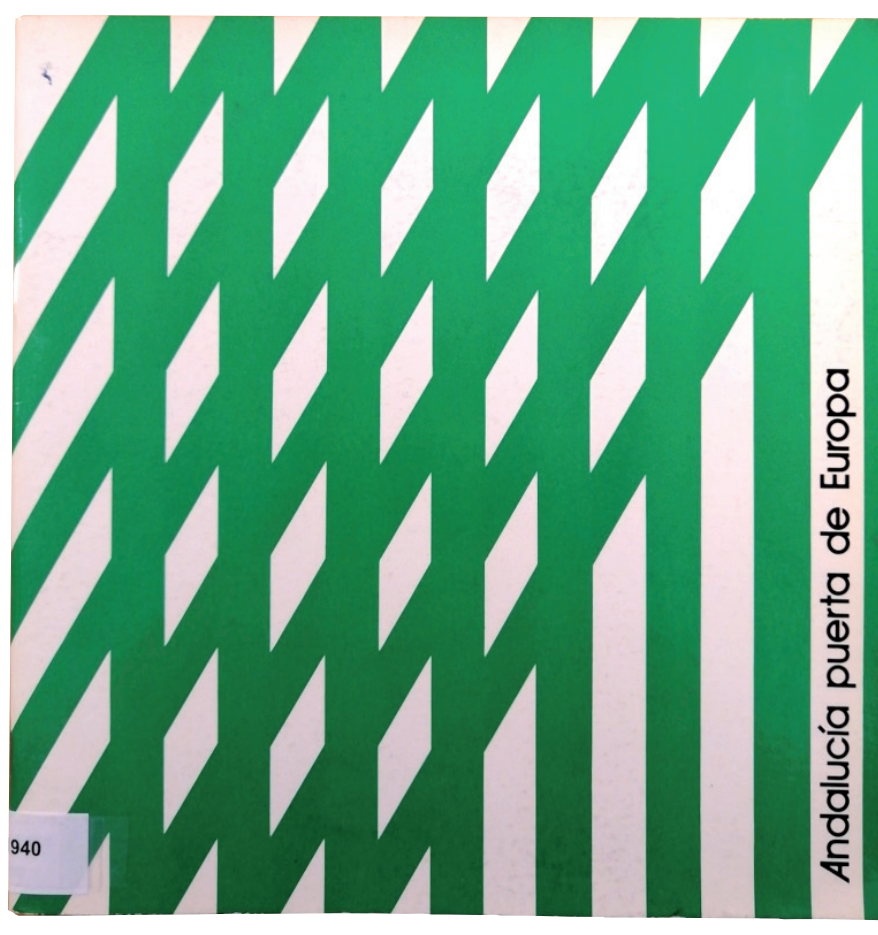

Fig. 3. Andalucía puerta de Europa. 1985. Catálogo. Consejería de Cultura, Junta de Andalucía, Sevilla. fueron utilizados como argumentos imprescindibles en la captación de la atención dentro y fuera de España, dentro de un escaparate que pretendía la atracción de inversión foránea y el aumento de los recursos económicos a través de un valor que se suponía iba a aumentar de modo exponencial con la entrada en el mercado común: el turismo. Como en otras tantas ocasiones, el rico bagaje y patrimonio culturales pasados y presentes eran puestos por la administración pública al servicio de intereses económicos y empresariales.

De modo inevitable los catálogos vinculados a dichas exposiciones, y sus correspondientes textos justificativos, han supuesto fuentes de primer orden para entender esos esfuerzos. De los catálogos conservados es posible verificar una doble vertiente con respecto a la cultura y las manifestaciones artísticas ya expresada.

Un primer esfuerzo expositivo llevó por título Andalucía puerta de Europa ${ }^{23}$. Fue comisariado por el arqueólogo y profesor universitario Ramón Corzo Sánchez, en aquel momento director del Museo de Cádiz y abarcaba desde el principio de los tiempos hasta fines del siglo XIX. El texto de investigación de dicho catálogo, titulado Huellas

\footnotetext{
21. "La exposición Andalucía, puerta de Europa ofrece una síntesis del pasado andaluz", ABC (ABC de Sevilla), 8 de noviembre de 1985, 17, consultado el 8 de julio de 2019, http://hemeroteca.sevilla.abc.es/nav/Navigate.exe/hemeroteca/sevilla/abc.sevilla/1985/11/08/017.html 22. "La exposición Andalucía, puerta de Europa...," 17.

23. Andalucía puerta de Europa (Sevilla: Consejería de Cultura, Junta de Andalucía, s. f.).
} 
de la Cultura Andaluza, fue encargado al historiador Antonio Domínguez Ortiz, quien al final de su exposición argumental reconocía la necesidad de auspiciar el conocimiento identitario, mediante la visibilización de sus huellas materiales e históricas, como "base firme de autoconciencia de un pueblo"24.

Si este primer hito expositivo mostraba una riqueza cultural histórica, otra paralela, bajo el título Arte actual: Andalucía Puerta de Europa ${ }^{25}$, pretendió proyectar la pujanza -en calidad y cantidad- de unas manifestaciones artísticas contemporáneas, ricas y singulares, pero también en consonancia con los lenguajes, dicciones, técnicas y campos creativos internacionales del momento. Javier Torres Vela, entonces consejero de cultura del gobierno andaluz, en el texto que servía de preámbulo apuntaba otro de los invariables referentes que iban a ser utilizados para dotar de personalidad a un arte andaluz con identidad propia: la diversidad ${ }^{26}$. Diversidad de personalidades, diversidad de enfoques, diversidad de influjos.

Los comisarios de la propuesta, María Corral e Ignacio Tovar, optaron por un inteligente planteamiento que sirviese a los intereses de la tesis global auspiciada por la administración impulsora. Primera y convenientemente, optaron por la lógica de incluir exclusivamente a artistas vivos $y$, en segundo lugar, por excluir a los muchos andaluces que trabajaban fuera del territorio y cuya vinculación con su lugar de origen les pareció muy escasa. Fue esta una cuestión controvertida y difícil de justificar pues circunscribían la condición andaluza a cuestiones geográficas o de militancia, lo que propició un debate acerca de quién podía ser considerado artista andaluz. Posteriormente dividieron la muestra en tres capítulos asimétricos que podríamos intitular como la contemporaneidad consagrada, el presente precursor y el futuro inmediato.

El primer espacio de visibilidad lo compusieron las obras de tres premios nacionales de Artes Plásticas pero muy distintos en su dicción: José Guerrero, Carmen Laffón y Luis Gordillo. El texto que situaba y evaluaba la trayectoria de los tres artistas en cuestión fue encargado a Juan Manuel Bonet, quien -además de otras interesantes apreciaciones- analizó la relación de los artistas con su locus de nacimiento y gestación creativa. La historia de Guerrero delineaba un recorrido que le llevó hacia la hibridación de la cultura artística y social aprehendida en Nueva York con el acento de lo español y lo andaluz que siempre subyace y termina por emerger. El devenir y estrategias de Carmen

24. Antonio Domínguez Ortiz, "Huellas de la cultura andaluza," en Andalucía puerta de Europa, s. p.

25. Arte Actual. Andalucía Puerta de Europa (Sevilla: Junta de Andalucía, 1985).

26. Javier Torres Vela, "Presentación," en Arte Actual. Andalucía Puerta de Europa, 5.

atrio Revista de Historia del Arte, no 26 (2020): 266 - 290

elSSN: 2659-5230. https://doi.org/10.46661/atrio.4568 
Laffón pasaban por la "rebelión caIlada, silenciosa, modosa"27 para con un academicismo adocenado. Finalmente, Bonet se detenía en la desastrosa relación de Gordillo con su ciudad natal, plagada de ausencias, reconocimientos a deshora, desencuentros y miradas desconfiadas en ambos sentidos.

El segundo conjunto lo conformaron artistas que antes de la década de los '80 ya poseían una carrera sólida y consolidada o en proceso de consolidación. El texto lo suscribió José A. Ýñiguez, quien se aprestó a señalar que los seleccionados no constituían un grupo de artistas ni

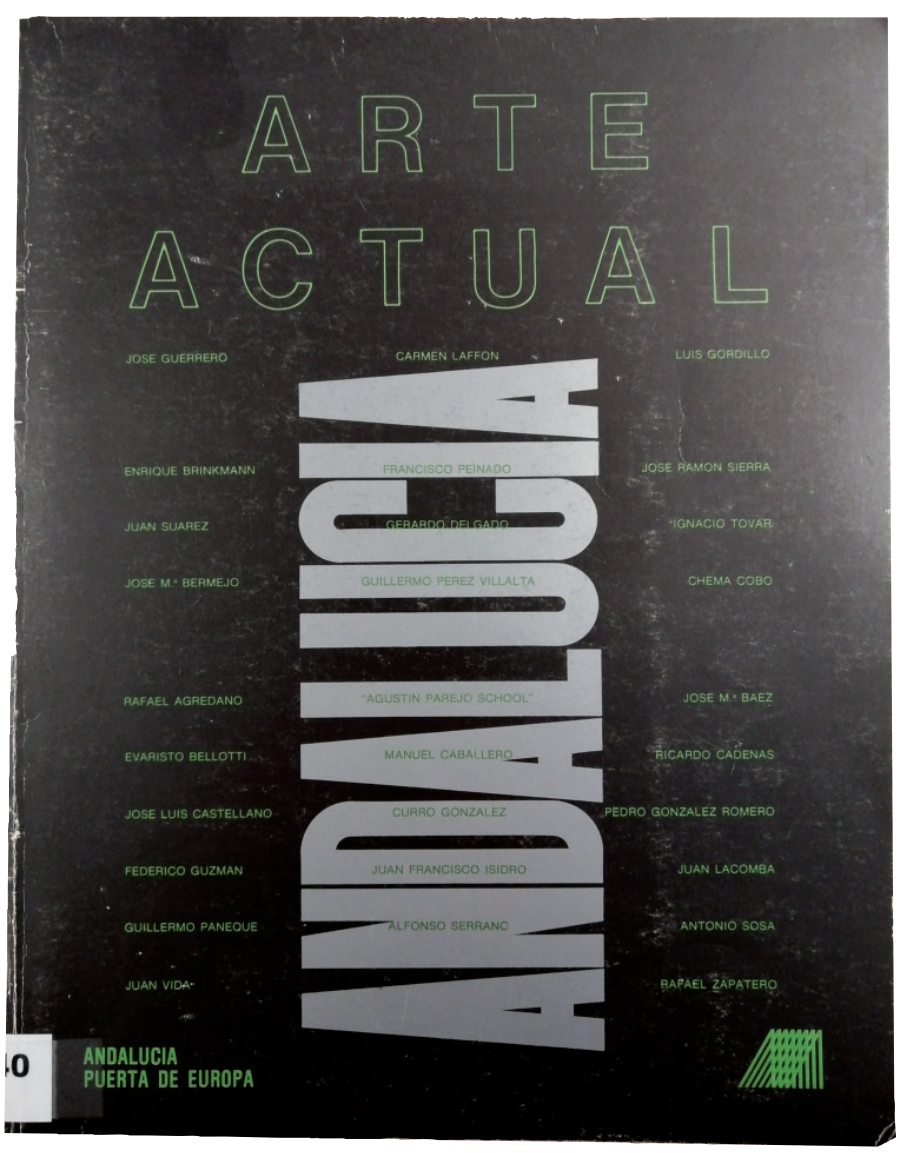

Fig. 4. Arte Actual. Andalucía puerta de Europa. 1985. Catálogo. Junta de Andalucía, Sevilla. por vinculaciones, objetivos ni por planteamientos teóricos o plásticos -señalando el error que supondría intentar forzar tales agrupaciones-, más allá de pertenecer a una generación y a un contexto cultural afín. Si remarcó que todos ellos "son (...) andaluces y sus obras lo confirman -cada uno de una forma personal y distinta-"28. Lo que no se aclaraba era dónde vislumbrar esa condición andaluza confirmada en las obras, si en el talante surrealista de Francisco Peinado, en la conjunción verbal vernácula -aunque partiendo de elementos americanos- que compartían Gerardo Delgado, José Ramón Sierra y Juan Suárez, en la contención ascética de Ignacio Tovar, o en las miradas siempre dirigidas al sur como lugar simbólico a la hora de pintar de Guillermo Pérez Villalta y Chema Cobo. Finalmente, un último grupo seleccionado por Kevin Power lo compusieron artistas jóvenes que habían comenzado a obtener visibilidad en esa misma década ${ }^{29}$.

27. Juan Manuel Bonet, "Tres obras clave," en Arte Actual. Andalucía Puerta de Europa, 12.

28. José A. Ýñiguez, "Apoyados en el quicio de la copla," en Arte Actual. Andalucía Puerta de Europa, 28.

29. Este último capítulo exhibió obras de Rafael Agredano, Agustín Parejo School, José Mạ Báez, Evaristo Bellotti, Manuel Caballero, Ricardo Cadenas, José Luis Castellanos, Curro González, Pedro G. Romero, Fede Guzmán, Juan Francisco Isidro, Juan Lacomba, Guillermo Paneque, Alfonso Serrano, Antonio Sosa, Juan Vida y Rafael Zapatero. 
La exposición, además, demostraba las relaciones de poder regionales en el ámbito artístico y cómo estas condicionaban la visibilidad interior y exterior, abriendo brechas al tiempo que manifestaban los distintos cronogramas presentes en el territorio andaluz a la hora de aceptar los presupuestos de la contemporaneidad plástica internacional. De tal modo resulta sencillo constatar cómo únicamente se seleccionaron dos artistas granadinos -Guerrero y Vida-, dos cordobeses -Báez y Agredano-, un artista nacido en Huelva -Pedro G. Romero- pero de formación absolutamente hispalense, y ningún artista de Almería o de Jaén. Todo ello venía a demostrar que la polarización creativa del momento se circunscribía a un triángulo cuyos vértices se situaban entre Sevilla, Cádiz y Málaga.

Es posible que esas miradas de identificación regional pudieran insertarse, como con perspicacia señalaba Power, dentro de corrientes compartidas por el arte europeo que auspiciaban un regreso hacia las raíces, hacia la herencia cultural ${ }^{30}$. Frente a los intereses políticos por delimitar la identidad de un arte vernáculo, los artistas se situaban en la tesitura paradójica de recuperar, con un sentido patrimonial, el bagaje cultural de lo propio y aceptar los influjos de culturas pujantes en aquel momento, tratando aquello que mejor conocían: "el lugar, el paisaje, la historia, la cultura que les rodea de manera inmediata. No es cuestión de provincianismos, sino de nuevos compromisos éticos ${ }^{\prime \prime 31}$.

Estos artistas, que para Power no conforman un grupo, se empeñaban "en la definición de un territorio -físico, imaginativo, intelectual- desde el que trabajar"32. Esto resultaba revelador: mientras los políticos trataban de superponer el marco territorial al espacio conceptual para el reconocimiento de "una realidad" (un arte andaluz como un todo unitario, con estatuto propio e independiente), los artistas iniciaban búsquedas y relaciones de modo particular en su entorno inmediato, cercano, como mecanismos para un mejor auto-conocimiento de "su realidad".

\section{Las miradas recopiladoras: 1988-2002}

Casi década y media separan dos exposiciones de muy distinto talante pero cuya finalidad fue la de recopilar y enmarcar los lenguajes de la contemporaneidad dentro del arte andaluz circunscribiéndose a un periodo de tiempo determinado. Una década, la

30. Kevin Power, "El alto volumen de la música," en Arte Actual. Andalucía Puerta de Europa, 66. 31. Power, 66.

32. Power, 63. 
década de la ilusión como fueron los ochenta, en el primer caso; y un periodo más largo, de dos décadas -desde fines de los cincuenta hasta finales de los años setenta del siglo pasado-, la segunda.

Comisariada por José Ramón Danvila, Andalucía. Arte de una década ${ }^{33}$ se exhibió en el Museo de Arte Contemporáneo de Sevilla, entre el 2 diciembre 1988 y el 10 enero 1989, y en el Hospital Real de Granada, entre el 20 enero y el 28 febrero de 1989. Desde las primeras líneas del texto catalogar, Danvila reconocía dos situaciones: en primer lugar se mostraba heredero de la exposición comisariada por Francisco Rivas titulada Pintores de Andalucía, ya citada líneas atrás, y, en segundo, asumía con naturalidad que la idea motriz era mostrar el arte generado en la región durante la década de vida de la autonomía andaluza.

En cierto modo, arte y política autonómica, se mostraban ya como esferas tangentes en las que las decisiones de la segunda condicionaban -y seguirían condicionando- la saludable vida de la primera. Danvila nos legó una serie de ideas en torno al arte andaluz y la asunción de unos parámetros contemporáneos que aún hoy podríamos defender como plenamente actuales: la certeza de que los andaluces habían ocupado una serie de capítulos claves en las conquistas culturales e históricas, del mismo modo que el ser andaluz había sido más proclive a la asimilación que a la difusión de sus logros. El peso de las tradiciones había hecho que los artistas hubieran sido capaces de avanzar desde estas "a base de pensar en ellas, de darle la vuelta y seguir aprovechándolas"34, aunque como punto negativo señalaba el éxodo de los creadores andaluces y un aislamiento con respecto a las noticias y flujos internacionales que les obligaron, en innumerables ocasiones, a vivir de las rentas de la historia y de la intuición.

La exposición se enmarcaba dentro del programa Andalucía 10 años, y el entonces consejero de cultura de la Junta de Andalucía, y futuro presidente del parlamento andaluz, el jiennense Javier Torres Vela, justificaba la actuación de la consejería en dos líneas paralelas de impulso con respecto a las exposiciones. Las dividía entre aquellas muestras colectivas que servían para promocionar dentro o fuera del país "a algunos artistas representantes de las últimas tendencias en nuestra comunidad"35 y otras que pretendían demostrar "con rotundidad la importancia que nuestra producción artística"36 poseía. Unas actuaciones, por lo tanto, que se hacían cara al exterior, reivindicando la actualidad del

33. Andalucía. Arte de una década (Sevilla: Consejería de Cultura, Junta de Andalucía, 1988).

34. José Ramón Danvila, "Introducción," en Andalucía. Arte de una década, 5.

35. Javier Torres Vela, "Presentación," en Andalucía. Arte de una década, 3.

36. Torres Vela, 3. 


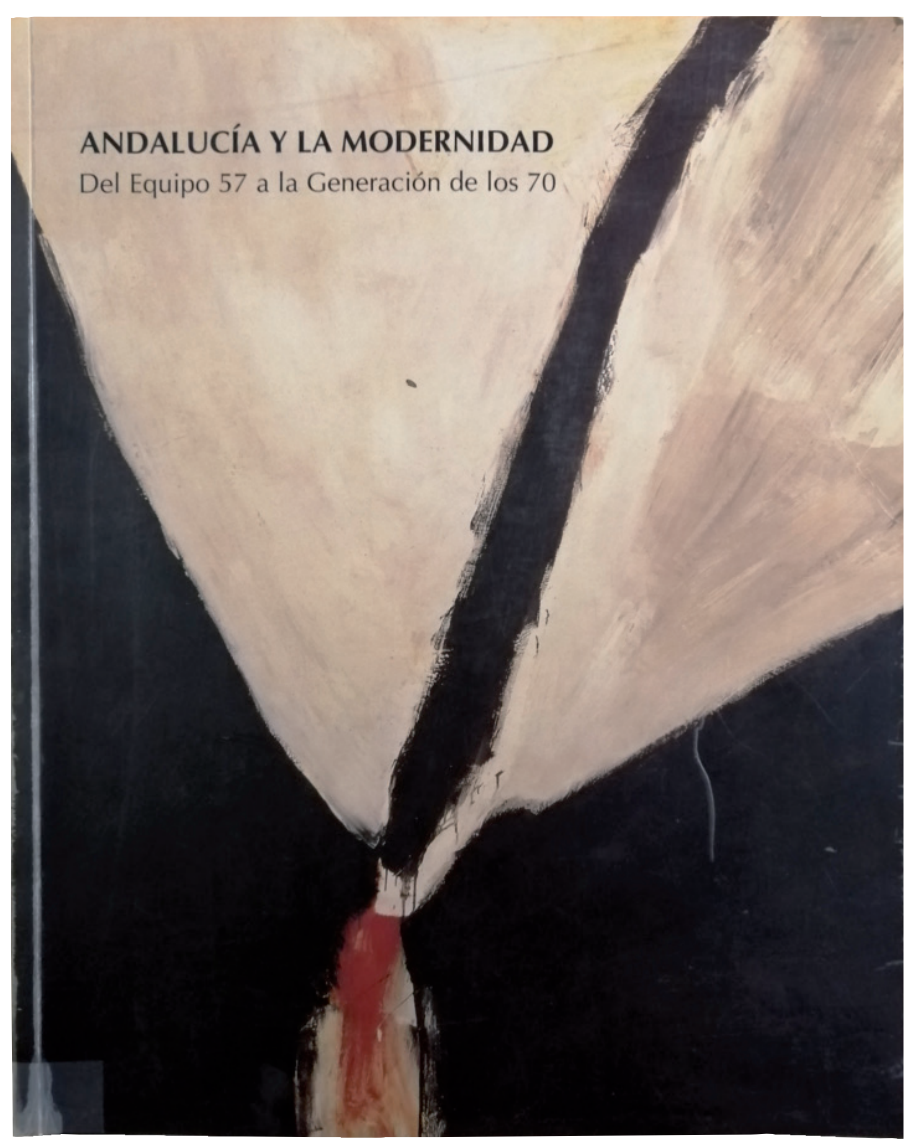

Fig. 5. Andalucía y la modernidad: del Equipo 57 a la generación de los 70. 2002. Catálogo. Centro Andaluz de Arte Contemporáneo, Sevilla. arte andaluz, que se sincronizaba con los modos del arte más avanzado a nivel nacional e internacional, y otras se producían hacia el interior, promoviendo el conocimiento y autoconvencimiento de la enorme capacidad del pueblo andaluz para producir -en cantidad y calidad- expresiones culturales de avanzada.

Catorce años después, en 2002, se inauguró en el Centro Andaluz de Arte Contemporáneo (CAAC), comisariada por Mariano Navarro, la ambiciosa muestra Andalucía y la modernidad. Del Equipo 57 a la generación de los $70^{37}$. Aquella exposición trataba claramente de mostrar las relaciones intercurrentes entre Andalucía y la idea de modernidad plás-

tica. El proyecto se enmarcaba dentro de una propuesta mayor que iba a contar con una segunda parte a modo de tesis expositiva y que abarcaría desde fines de los setenta hasta el nuevo siglo, examinando las complejas décadas -que en el contexto andaluz se tradujeron en un amplio florecimiento y posterior crisis de las artes plásticas- de los ochenta y noventa del siglo pasado. Pero esa segunda parte, aún hoy tan necesaria, nunca se desarrollaría más que de modo fragmentario.

Si en palabras del entonces director de la institución, José Antonio Chacón, la muestra venía a ofrecer una contextualización en torno a medio siglo de arte contemporáneo andaluz, esta ponía el acento en dos vértices conceptuales que vendrían repitiéndose a lo largo del presente análisis: Io "original vernáculo" y la "confluencia internacional". La propuesta permitía, por un lado, "acercar obras, tendencias y lenguajes que han nacido con acento andaluz" y establecer los "vínculos de Andalucía con las tendencias

37. Andalucía y la modernidad. Del Equipo 57 a la generación de los 70 (Sevilla: Centro Andaluz de Arte Contemporáneo, Consejería de Cultura, 2002). 
contemporáneas, tanto en su vertiente de aportación original como de influjo de otras procedencias $^{\prime \prime 38}$.

Las tesis de los profesionales de la cultura no suponen más que un eco del discurso que se traza desde el ámbito político y que encuentra perfecto ejemplo en el preámbulo que delinea Manuel Chaves, entonces presidente de la Junta de Andalucía, cuando avala al Centro Andaluz de Arte Contemporáneo como depositario de un capítulo fundamental de la memoria histórica andaluza y a la propia exposición como espejo de la misma por cuanto reflejan que "es un hecho que la democracia y la consolidación del modelo autonómico han determinado un profundo cambio cualitativo y cuantitativo, que afecta tanto a la normalización de las instituciones como a la propia actitud de los andaluces, agrupados ahora en torno a una idea de Andalucía que, desde la solidez y la solidaridad, se proyecta hacia un mundo más globalizado (...) Estas obras son una síntesis de la aportación de los andaluces y andaluzas a la evolución del arte del siglo XX y, al mismo tiempo, dibujan un espacio para el encuentro, el debate y la reflexión"39.

Como bien indicaba en uno de los textos de ese mismo catálogo el profesor Carmona, esa relación, desgraciadamente, fue siempre insatisfactoria, tal vez porque su práctica estuvo lastrada por no contar "con un escenario artístico propio" 40 como si tuvieron, además de la capital madrileña por razones obvias, País Vasco y Cataluña, donde las demandas nacionalistas impusieron un diálogo entre identidad y modernidad que generó unas dicciones singulares.

\section{Un nuevo siglo: nuevos formatos y nuevas exploraciones}

En 2002, mismo año de la propuesta revisionista Andalucía y la modernidad, se desarrolló en la Sala Villasís del Centro Cultural El Monte, en la capital sevillana, un proyecto expositivo que llevaba por título Muestra de Arte Contemporáneo Andaluz ${ }^{41}$, desarrollada entre enero y marzo del citado año42. Comisariada por José A. Yñiguez, la preten-

38. José Antonio Chacón, "Presentación," en Andalucía y la modernidad. Del Equipo 57 a la generación de los 70, 16.

39. Manuel Chaves González, "Presentación," en Andalucía y la modernidad. Del Equipo 57 a la generación de los 70, 11.

40. Eugenio Carmona, "Sísifo andaluz o breve prehistoria en torno a las relaciones entre Andalucía y el arte moderno," en Andalucía y la modernidad. Del Equipo 57 a la generación de los 70, 31.

41. Muestra de Arte Contemporáneo Andaluz (Sevilla: Fundación El Monte, 2002).

42. La exposición seleccionó y exhibió obras de Pilar Albarracín, Tete Álvarez, Patricio Cabrera, Curro González, Dionisio González, Pedro G. Romero, Federico Guzmán, Joaquín Yvars, Abraham Lacalle, Rogelio López Cuenca, Pedro Mora, Gonzalo Puch, Juan Carlos Robles, Antonio Sosa y Javier Velasco. 


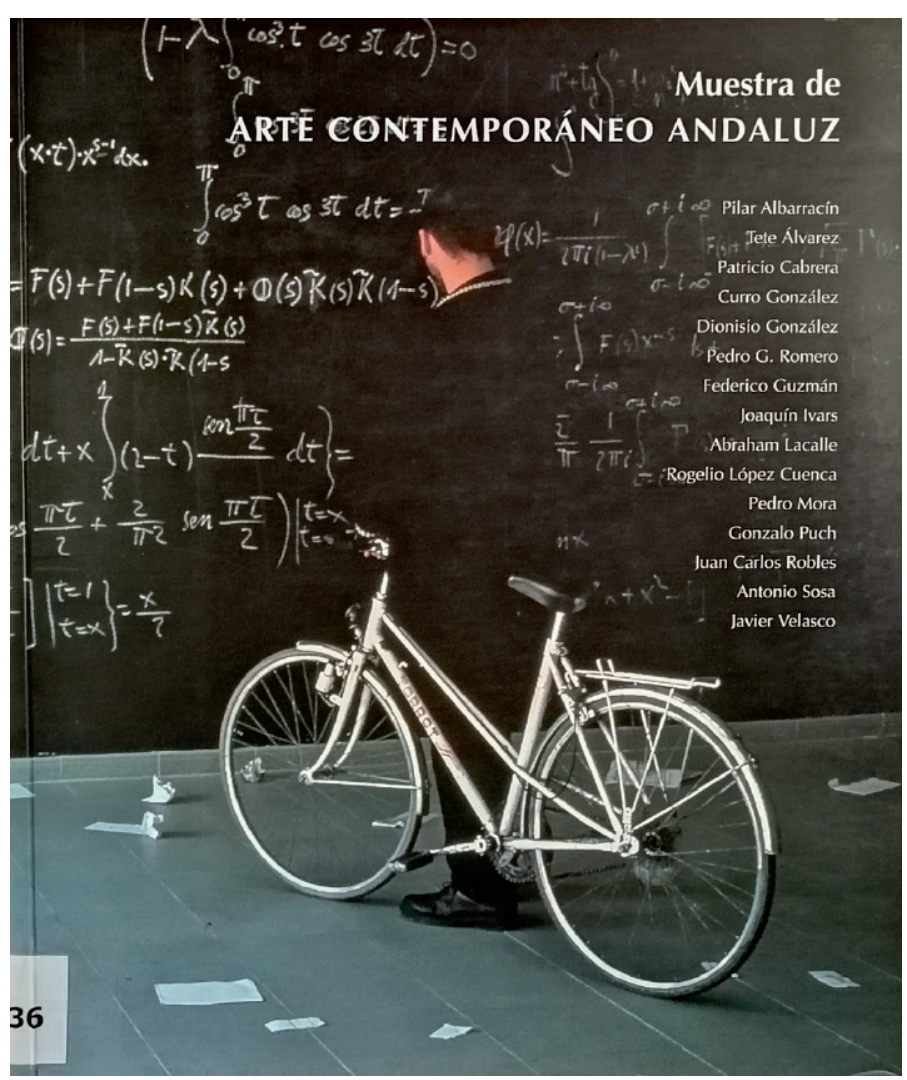

Fig. 6. Muestra de arte contemporáneo andaluz. 2002. Catálogo. Fundación El Monte, Sevilla. sión de esta muestra era múltiple. Se proponía poner de manifiesto el momento concreto que estaba transitando el arte andaluz, ofrecer visibilidad a una serie de creadores que estaban renovando el panorama regional y nacional y, finalmente, permitir un ejercicio reflexivo sobre la actualidad y el futuro del arte en Andalucía ${ }^{43}$.

El texto que servía de preámbulo al catálogo y que se titulaba Acaso. Diálogo en un atardecer de invierno se articulaba como un singular diálogo entre dos curiosos personales antagónicos, Acaso y Nicaso. Ambos enfrentaban sus pareceres tanto en torno a problemáticas secula-

res cuanto a distintos puntos capitales de la plástica y la estética andaluza de mayor actualidad. Uno de estos desencuentros bascula sobre la tradición y los tradicionalismos en relación con el desarrollo de la contemporaneidad. Sobrarían tradicionalismos y faltaría una verdadera conciencia de una tradición de logros y novedades alcanzados por los andaluces. La narración y evaluación histórica de tales logros habría sido dejada en manos de eruditos -cuando no de entusiastas aficionados- que habrían transmitido una idea arquetípica y folclórica de la realidad. Se afirma que con la excepción de trayectorias individuales y de modo más generalizado durante de la década de los ochenta, y aun así en precarias condiciones, el arte contemporáneo como tal no ha existido en el territorio andaluz.

De nuevo, en la conversación, emergía el tópico, tan real como subjetivo, del número y calidad de los artistas, donde lo andaluz se siente capacitado para entrar en competencia de igualdad y condiciones con lo foráneo, pues con respecto al resto: "Aún hay carencias de todo tipo, no existe verdadera política institucional que fomente la creación artística ni eduque al espectador (...) Tampoco existe un mercado lo suficientemente extenso

43. José A. Ýñiguez, "Presentación," en Muestra de Arte Contemporáneo Andaluz, 9. 
como para mantener la propia producción artística y, por lo tanto, tampoco existen suficientes galerías con vocación de apostar por el arte contemporáneo que puedan aumentarlo. Todo ello unido a la falta de medios de comunicación con influencia en el exterior, hace de Andalucía un lugar periférico situado en las afueras de la periferia del sistema"44.

Como indicaba el contertulio Nicaso, y como han señalado antes y después otros teóricos, esas dificultades podrían transformarse en el hecho diferencial de las artes en Andalucía, siempre en constante conflicto, aunque Acaso termine de convencerse:

Tampoco es posible distinguir a estas alturas particularidades regionales que marquen a los artistas y los encuadren en escuelas regionales. Cualquier referencia a cualquiera de las particularidades que se puedan considerar como regionales, sin duda tiene valor e intención pero no autoridad sobre el carácter de la obra. El ritmo de vida, el clima, la historia común y otras mil, o más de mil variables, determinan unas particularidades estadísticas que confieren carácter individual a un ámbito geográfico, pero la creación artística actual, aun cuando pueda incidir sobre ellas o tomarlas como punto de partida, no tiene ninguna vocación de convertirse en relicario de las mismas ${ }^{45}$.

En 2006, en el marco de la segunda edición de la BIACS (Bienal Internacional de Arte Contemporáneo de Sevilla), se inauguró en la Sala Villasís del Centro Cultural EI Monte, la exposición The Sock Strategy. La Estrategia del Calcetín ${ }^{46}$ comisariada por Iván de la Torre Amerighi.

El comisario de la muestra desglosaba los objetivos de la exposición, incluida dentro de la oferta periférica de una bienal artística de cariz internacional, entre los que destacaba la voluntad de "hacer visibles. Ver y ser vistos. Convocar la atención hacia el conocimiento del joven arte andaluz. Dejar testimonio futuro de ello (...) Potenciar y conectar las relaciones artísticas más internacionales y globales con aquellas más cercanas y genuinas proyectando, de tal modo, la validez universal, el carácter supranacional del arte andaluz actual y contemporáneo. Ello requería la interacción de un proyecto expositivo que operara a mayor profundidad que la mera exhibición, que interactuara en (y con) la realidad y el orden interno de la dinámica cultural y artística a nivel autonómico"47.

Quedaron fuera aquellos artistas que, cumpliendo con las premisas marcadas -ser artistas andaluces menores de 35 años- ya habían sido seleccionados para la participación en el

44. José A. Ýñiguez, "Acaso. Diálogo en un atardecer de invierno," en Muestra de Arte Contemporáneo Andaluz, 20-21.

45. Ýñiguez, 21.

46. The Sock Strategy. La estrategia del calcetín (Sevilla: Fundación El Monte, 2006).

47. Iván de la Torre Amerighi, "Justificación expositiva," en The Sock Strategy. La estrategia del calcetín, 15. 
programa genérico de BIACS II, que llevó por título Lo desacogedor. Escenas fantasmas en la sociedad global. Estos creadores fueron Miki Leal, Jacobo Castellano y MP \& MP Rosado Garcés, pues la voluntad última del proyecto era demostrar que el arte joven andaluz poseía el mismo vigor plástico y validez intelectual que las manifestaciones artísticas que había sido seleccionadas por el comisario, historiador del arte y poeta nigeriano Okwui Enwezor para ser mostradas en el evento internacional.

El proyecto contó con el apoyo de Consejería de Cultura de la Junta de Andalucía, el Ayuntamiento de Sevilla, la Fundación Biacs y la Fundación El Monte. En el espacio expositivo de esta última institución -en la actualidad Espacio Atin Aya dependiente del Ayuntamiento de Sevilla- se exhibieron entre el 4 de octubre y el 30 de noviembre de 2008 obras e instalaciones de 29 artistas andaluces o afincados en Andalucía. Las realizaciones y piezas de los creadores fueron ordenadas en 6 líneas capitulares (El Elogio de la irreverencia, la Subversión de lo real, el Sujeto-Objeto, Escenografías y Máscaras, Esplendores cotidianos y Paisajes distópicos) que quedaban separadas por una singular organización museográfica diferencial, bajo la dirección del artista Paco Pérez Valencia, controvertida en la época y ampliamente imitada inmediatamente después.

Sin pretender establecer los parámetros de "lo andaluz" en el arte joven de la región, el comisario sí mencionaba distintos "factores de singularización" que se transformaban en desencadenantes de la creatividad o, más bien, en obstáculos que la condicionaban y dotaban de personalidad propia en un proceso que se repetía en todas las provincias andaluzas. Entre esos factores destacaban: un aprendizaje circunscrito a ámbitos docentes amanerados, academicistas e inmovilistas; la confrontación cotidiana con estructuras socio-culturales frecuentemente recelosas, cuando no hostiles, hacia lo contemporáneo y la convivencia con un patrimonio monumental y etnográfico abrumador, en muchos sentidos insuperable y siempre atosigante. También se señalaban una base social connivente con la(s) tradición(es), malentendidas estas como únicas vías de expresión creativa y obtención de belleza estética, y la ausencia secular de un tejido -bien mercantil o institucional- volcado con el mecenazgo y apoyo para con la innovación y experimentación creativa.

Estos hechos diferenciales, que podrían quedar resumidos en una constante política del enfrentamiento, habrían sido compartidos, de un modo u otro, por todos los artistas andaluces contemporáneos, lo que "además de formar un carácter recio y forjar un espíritu colectivo, pueden haber posibilitado unas pautas cohesivas comunes a la hora 
de edificar un lenguaje traductor para con el mundo circundante" ${ }^{\prime \prime 8}$.

Para el comisario, este factor de enfrentamiento, esta constante situación de combate (en y con la sociedad) y este rosario de proyectos y promesas incumplidos (por parte de las instituciones culturales y las esferas políticas), serían los que habrían llevado a gran parte del arte andaluz contemporáneo a subsistir en un constante punto intermedio entre la "mentalidad de la decepción" y la "idealización ilusionada": "Tras vivir con desolación la defección de unas ilusiones y objetivos imposibles de

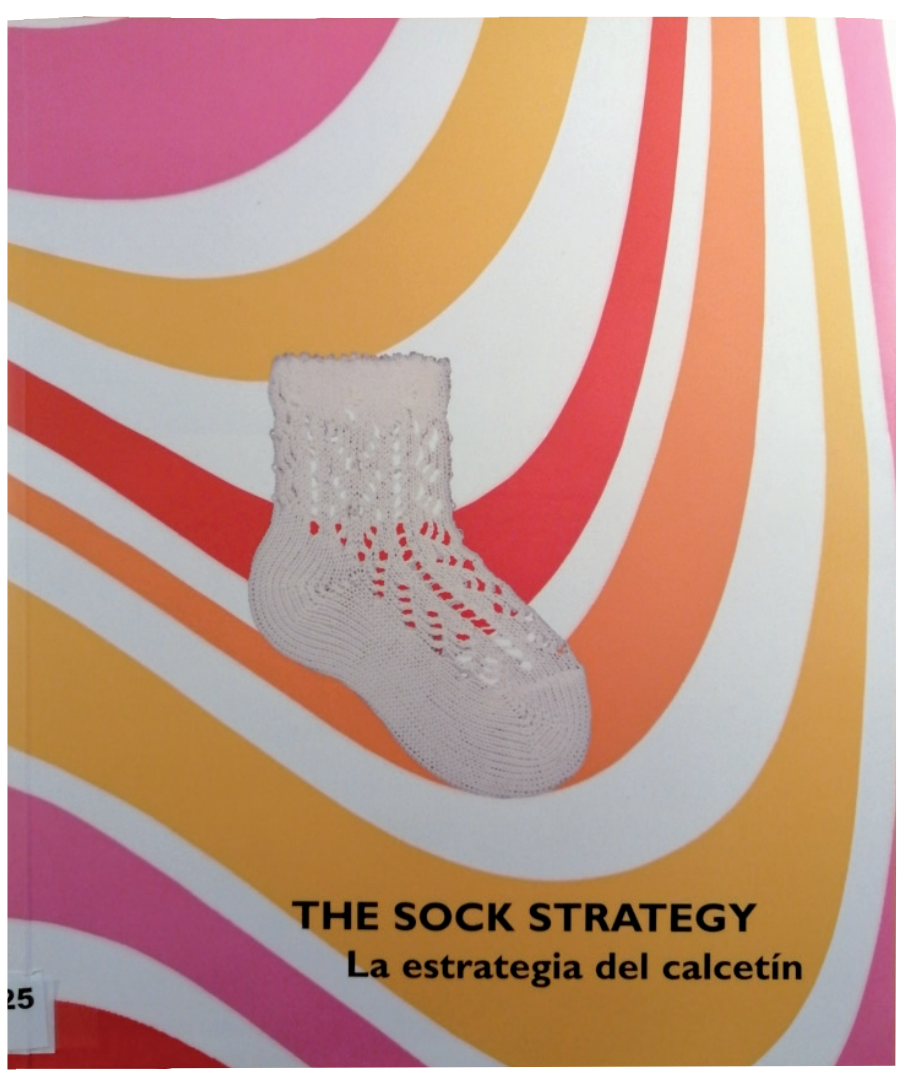

Fig. 7. The Sock Strategy. La estrategia del calcetín. 2006. Catálogo. Fundación El Monte, Sevilla. cumplir; hastiados de la lucha y sin poder asumir el oneroso coste moral y anímico de la refriega, a emigrar; bien con la literalidad que marca el término, buscando nuevos horizontes creativos y profesionales fuera de Andalucía; bien metafóricamente, plegando velas, emboscándose en un exilio interior, silentes, decepcionados y alejados de toda ceremonia cultural"49.

El tono en exceso pesimista del texto puede que derivase de los momentos en los que fue escrito. Ya en 2008, si no se constataba, sí se barruntaba la nueva crisis económica que se sobrevenía y que impactaría de nuevo con extrema fuerza sobre el frágil armazón de la cultura andaluza. También se vislumbraba que ello traería consigo el final de los esfuerzos hasta el momento articulados -véase la difícil supervivencia hasta su desaparición del Programa Iniciarte- para impulsar la identidad de un arte andaluz y fomentar su conocimiento a partir de unos mecanismos como las exposiciones y los catálogos, herramientas que progresivamente iban a ser sustituidas por otros formatos.

48. De la Torre Amerighi, 17.

49. Iván de la Torre Amerighi, "Usted se preguntará por qué cantamos," en The Sock Strategy. La estrategia del calcetín, 23. 
A partir de la segunda mitad de la primera década del siglo XXI y hasta bien entrada la siguiente resulta posible encontrar una serie de propuestas que, tal vez influenciadas por los nuevos formatos de catalogación aparecidos a nivel internacional de la mano de editoriales como Taschen o Phaidon, trataron de parcelar un ámbito concreto de una determinada realidad artística. Y lo plasmaron mediante unas herramientas de indagación que podrían ser consideradas como guías de "una exposición imaginaria, en las que cada artista dispone del mismo espacio y en la que la concatenación entre ellos se debe al azar, al orden alfabéticos de sus nombres"50. Entre esos nuevos formatos en los que Andalucía fue pionera es posible citar Arte desde Andalucía para el siglo XX|51, cuyos dos tomos fueron presentados en ARCO 2008, y Stand By_012. Guía de la Fotografía Andaluza Actual ${ }^{12}$.

\section{Conclusiones}

La efervescencia de la década de los ochenta, en cuanto a la profusión expositiva y catalogar que documentan y defienden la singularidad e importancia de unas nuevas generaciones de artistas andaluces, resultó imposible de mantener con idéntica intensidad durante los siguientes lustros, aunque se perpetuasen los modelos hasta bien entrado el siglo XXI.

Las causas de estas defecciones han sido variadas y complejas, pero entre ellas cabría destacar la progresiva reducción de los presupuestos culturales públicos, la consolidación del Estado de las autonomías y la visión de la defensa del hecho diferencial como un anacronismo, las sucesivas crisis económico-sociales de principios de la década de los noventa y de fines de la primera década del nuevo siglo, la progresiva globalización de los lenguajes artísticos y la difusión internacional que alcanzan de modo particular a algunos creadores andaluces.

Todo ello ha venido enfriando la voluntad o necesidad de defender una dicción o, al menos, unos ademanes lingüísticos propiamente singulares. Por otro lado se ha descubierto la necesidad de dotarse de catálogos-inventario que parcelen y estudien casos concretos y específicos dentro del arte producido desde Andalucía o por andaluces, más allá del espacio limitado que permite el catálogo expositivo.

50. Burkhard Riemschneider y Uta Grosenick, "Prólogo," en Arte de hoy (Colonia: Taschen, 2001), 7.

51. Iván de la Torre Amerighi, coord., Arte desde Andalucía para el siglo XXI (Sevilla: Consejería de Cultura, Junta de Andalucía, 2008).

52. Sema D'Acosta, ed., Stand By_012. Guía de la Fotografía Andaluza Actual (Sevilla: Fundación Valentín de Madariaga, 2012). 
A lo largo de los diferentes ejemplos escogidos que se han ido sucediendo a lo largo de tres décadas, ya se debieran a impulsos políticos o derivasen de iniciativas privadas, ha podido constatarse cómo los argumentos en torno a los rasgos diferenciales de la plástica andaluza, convenientemente perfilados y matizados, se han perpetuado en el tiempo. Conceptos como la abundancia y calidad de la producción artística andaluza se han visto anudados a la noción de una personalidad creativa flexible y permeable que ha permitido alcanzar una sensibilidad distintiva e híbrida, que fusiona el bagaje de siglos de historia y tradición con aportes foráneos, exógenos. Esta última consideración gira en torno a la confluencia sin complejos de los originales conceptos estéticos y artísticos vernáculos, lo que se ha sido denominado como "acento andaluz", con lenguajes, modos y modelos vigentes en cada momento determinado en la escena internacional aceptados como lengua franca.

Dos elementos más suelen repetirse en los discursos vistos. El primero es la dialéctica de la confrontación y la incomprensión que comparten los creadores andaluces con respecto a un entorno ensimismado en los tradicionalismos y carente de estructuras docentes, institucionales y mercantiles mínimamente sólidas. De este enfrentamiento ha pervivido la idea de un artista andaluz autosuficiente, acostumbrado a la superación de obstáculos y a la falta de ayudas. Dentro de los procesos que ayudan a la disolución de la hostilidad y a la trasformación de premisas negativas en situaciones provechosas destacan sobre los demás la constante utilización, en distintos grados, de la ironía y el escepticismo.

El segundo elemento, mucho más complejo de delinear es el de una suerte de ethos o forma de comportamiento social colectivo que, en los artistas, se sustancia en la asunción como verdadero de un estadio -Andalucía- que es al tiempo real, imaginario y conceptual y un sentimiento de nostalgia permanente. Nostalgia compartida por quienes trabajan desde el territorio (en una suerte de exilio interior) y quienes viven fuera de él (desplazados de un medio que es rememorado constantemente).

En suma, en los numerosos textos catalogares que se han ido revisitando en las presentes páginas se repiten ciertos arquetipos presentes, tal vez invariantes, que ya desgranaba en 1923 Francisco Cuenca en su obra Museo de pintores y escultores andaluces ${ }^{53}$, interesante precedente de los compendios artísticos de nuevo formato que han eclosionado a finales del siglo XX y principios del XXI. El prólogo de dicha publicación, debido al dramaturgo y poeta almeriense Francisco Villaespesa, destila una honda y curiosa

53. Francisco Cuenca, Museo de pintores y escultores andaluces (La Habana: Rambla, Bouza y Cía, 1923). 
actualidad. En este se denunciaban los tópicos y la leyenda pintoresca de Andalucía, se reconocía la importancia de los condicionantes ambientales y climáticos, la predisposición e intuición natural, la preponderancia de una tradición secular así como un folclore particular que condicionaba un desarrollo lento y trabajoso de la cultura y la sociedad. Aparecían ya, como notas distintivas de la creatividad andaluza, la cantidad porcentual de artistas que la tierra producía, la capacidad de absorción, deglución y reinvención de la cultura para con los influjos externos, la alegría dolorosa y cierta nostalgia consoladora y estimulante ${ }^{54}$.

\section{Referencias}

Andalucía. Arte de una década (Sevilla: Consejería de Cultura, Junta de Andalucía, 1988).

Andalucía puerta de Europa (Sevilla: Consejería de Cultura, Junta de Andalucía, s. f.).

Andalucía y la modernidad. Del Equipo 57 a la generación de los 70 (Sevilla: Centro Andaluz de Arte Contemporáneo, Consejería de Cultura, 2002).

Andana 7. Pintores andaluces que viven fuera de Andalucía (Cádiz: Diputación Provincial de Cádiz, 1982).

Arte Actual. Andalucía Puerta de Europa (Sevilla: Junta de Andalucía, 1985).

Bonet, Juan Manuel. "Tres obras clave." En Arte Actual. Andalucía Puerta de Europa, 8-13. Sevilla: Junta de Andalucía, 1985.

Campoy, Antonio Manuel. "Pintores andaluces en Madrid." En Pintores Andaluces en Madrid, s.p. Granada: Caja General de Ahorros y Monte de Piedad de Granada, 1988.

Carmona, Eugenio. "Sísifo andaluz o breve prehistoria en torno a las relaciones entre Andalucía y el arte moderno." En Andalucía y la modernidad. Del Equipo 57 a la generación de los 70, 29-35. Sevilla: Centro Andaluz de Arte Contemporáneo, Consejería de Cultura, 2002.

Chacón, José Antonio. "Presentación." En Andalucía y la modernidad. Del Equipo 57 a la generación de los 70, 15-17. Sevilla: Centro Andaluz de Arte Contemporáneo, Consejería de Cultura, 2002.

Chaves González, Manuel. "Presentación." En Andalucía y la modernidad. Del Equipo 57 a la generación de los 70, 11. Sevilla: Centro Andaluz de Arte Contemporáneo, Consejería de Cultura, 2002.

Cuenca, Francisco. Museo de pintores y escultores andaluces. La Habana, Cuba: Rambla, Bouza y Cía, 1923.

D’Acosta, Sema, ed. Stand By_012. Guía de la Fotografía Andaluza Actual. Sevilla: Fundación Valentín de Madariaga, 2012.

Danvila, José Ramón. "Introducción." En Andalucía. Arte de una década, 5-7. Sevilla: Consejería de Cultura, Junta de Andalucía, 1988.

54. Francisco Villaespesa, "Prólogo," en Cuenca, Museo de pintores, 17-27. 
De la Torre Amerighi, Iván. "Justificación expositiva." En The Sock Strategy. La estrategia del calcetín, 15-18. Sevilla: Fundación El Monte, 2006.

---. "Usted se preguntará por qué cantamos." En The Sock Strategy. La estrategia del calcetín, 21-23. Sevilla: Fundación El Monte, 2006.

---, coord. Arte desde Andalucía para el siglo XXI. Sevilla: Consejería de Cultura, Junta de Andalucía, 2008.

Domínguez Ortiz, Antonio. "Huellas de la cultura andaluza." En Andalucía puerta de Europa, s.p. Sevilla: Consejería de Cultura, Junta de Andalucía, s. f.

Gala, Antonio. "Palabras ante una exposición." En Andana 7. Pintores andaluces que viven fuera de Andalucía, s.p. Cádiz: Diputación Provincial de Cádiz, 1982.

Gállego, Julián. "Pintores andaluces desde 1900." En Pintores andaluces desde 1900, s.p. Granada: Banco de Granada, 1977.

I Exposición de pintores andaluces contemporáneos (Sevilla: Universidad de Sevilla, 1978).

"La exposición Andalucía, puerta de Europa ofrece una síntesis del pasado andaluz." ABC (ABC de Sevilla), 8 de noviembre de 1985. Consultado el 8 de julio de 2019. http://hemeroteca. sevilla.abc.es/nav/Navigate.exe/hemeroteca/sevilla/abc.sevilla/1985/11/08/017.html

Marzo, Jorge Luis. "Lo moderno como antimoderno. Apuntes sobre el arte oficialista español en la época de la Transición." En El poder de la imagen. La imagen del poder, editado por Margarita Ruiz Maldonado, Antonio Casaseca, y Francisco Javier Panera Cuevas, 119-218. Salamanca: Ediciones Universidad de Salamanca, 2013.

Moreno Galván, José María. "Prólogo." En I Exposición de pintores andaluces contemporáneos, s.p. Sevilla: Universidad de Sevilla, 1978.

Muestra de Arte Contemporáneo Andaluz (Sevilla: Fundación El Monte, 2002).

Pintores andaluces desde 1900 (Granada: Banco de Granada, 1977).

Pintores andaluces en Madrid (Granada: Caja General de Ahorros y Monte de Piedad de Granada, 1988).

Pintores de Andalucía (Bilbao: Museo de Bellas Artes de Bilbao, 1982).

Power, Kevin. "El alto volumen de la música." En Arte Actual. Andalucía Puerta de Europa, 6267. Sevilla: Junta de Andalucía, 1985.

Revilla Uceda, Miguel-Ángel. "Prólogo."En Pintores andaluces desde 1900, s.p. Granada: Banco de Granada, 1977.

---. José María Rodríguez Acosta, 1878-1941. Madrid: Turner, 1992.

Riemschneider, Burkhard y Uta Grosenick. "Prólogo." En Arte de hoy, 6-7. Colonia: Taschen, 2001.

Rivas, Francisco. "Elogio de los que se fueron." En Andana 1. Pintores andaluces que viven fuera de Andalucía, s.p. Cádiz: Diputación Provincial de Cádiz, 1982.

---. "Rompecabezas andaluz. Notas sobre la historia del Arte Moderno en Andalucía." En Pintores de Andalucía, s.p. Bilbao: Museo de Bellas Artes de Bilbao, 1982.

The Sock Strategy. La estrategia del calcetín (Sevilla: Fundación El Monte, 2006).

Torres Vela, Javier. "Presentación." En Arte Actual. Andalucía Puerta de Europa, 5. Sevilla: Junta de Andalucía, 1985. 
---. "Presentación." En Andalucía. Arte de una década, 3. Sevilla: Consejería de Cultura, Junta de Andalucía, 1988.

Ýñiguez, José A. "Apoyados en el quicio de la copla." En Arte Actual. Andalucía Puerta de Europa, 28-31. Sevilla: Junta de Andalucía, 1985.

---. "Acaso. Diálogo en un atardecer de invierno." En Muestra de Arte Contemporáneo Andaluz, 11-21. Sevilla: Fundación El Monte, 2002.

---. "Presentación." En Muestra de Arte Contemporáneo Andaluz, 9. Sevilla: Fundación El Monte, 2002.

Villaespesa, Francisco. "Prólogo." En Museo de pintores y escultores andaluces, Francisco Cuenca, 17-27. La Habana: Rambla, Bouza y Cía, 1923. 